\title{
An Intelligent Virtual Reality Model for Site Layout Planning
}

\author{
Dr. A. H. Boussabaine, School of Architecture and Building \\ Engineering, The University of Liverpool, PO Box 147, Liverpool, L69 3BX.
}

\begin{abstract}
:
This paper describes research which is underway in the School of Architecture and Building Engineering at the University of Liverpool. The main aim of the first stage of this research is to develop a theoretical model for site layout visulaisation. Emphasis has been placed on investigating ways of integrating and representing the site layout information in an electronic model that can be easily used by site planners.

The paper reviews the available literature. The method for knowledge elicitation and representation is described. A conceptual paper model is presented and its structure and modules are described.
\end{abstract}

\section{Introduction}

Site layout planning consists of identifying the facilities needed to support construction operations, determining their size and shape, and positioning them within the boundaries of the site ( $\mathrm{Rad}, 1983$, Gibb 1995). The formulation of the construction site layout problem is that a set of facilities needs to be located on the site, while optimising layout objectives and satisfying a set of layout constraints. The allocation of space to temporary facilities is a complex construction management task. There are many factors that need to be taken into account. Planners and managers rely on trial and error and the use of partial layouts from previous job sites for constructing layouts that meet a project and its site's requirements ( Cheng, 1994, Tommelein 1992). Drawings are used to convey the site layout principles throughout construction of the project but rarely updating them as construction progress. Because so many changes take place over time, updating drawings to keep track of all facilities is a prerequisite for a safe construction site. Site layout drawings are a superimposition of several site layouts, each pertaining to a different period. Any person who is to interpret such drawings needs good spatial and temporal conceptualisation skills (Tommelein 1991). Dynamic visual aids and more standard layout methods can facilitate visualisation, interpretation and identify beforehand any health and safety problems that may occur during the construction period. Dynamic visual aids make it easy for planners to visualise components of the site layout problem. Common visual aids include icons, drawings, sketches, templates, and two or three-dimensional scale models. Among these visual aids templates are the most widely used in the trial and error process of fitting pieces together in order to achieve satisfying layouts. However, this approach lacks animation and immersion of the user into the real world of site layout planning environment. The use of animated templates and three-dimensional models might help to achieve a real interactive computer site layout planning environment allowing planners to select temporary facilities and move them around in a real world environment. This representation has an advantage over other methods in that it represents to scale more spatial relations between the site 
layout components. Template and 3D objects can be defined not only geometrically but also contain other information about material, plant etc., location and their position in a construction schedule. In this approach, the planners will have the feeling and experience of being virtually immersed with the facilities to be located.

Although this approach help planners to explore alternative solutions in a real environment, it does not give any guidance towards which alternatives to pursue. Nor do they help a planner remember which arrangements were previously generated. Therefore, a knowledge base on the context in which these templates and three dimensional objects are applied is essential for the successful use of such a system as a decision making tool. Therefore, this research uses VR tools and AI techniques for modelling an intelligent VR system for planning the layout of construction sites in a virtual environment before working on them. AI techniques are used to classify facilities that are used on construction sites, constraints between them, to represent rule of thumb on facilities location, to provide guidance on sizes of such typical facilities, to provide a description of layouts used on similar projects and to provide detailed explanation for novices, users or planners. With a rapid search mechanism and fast query routines such a knowledge- intensive system then makes problem solving easier and produces tailored solutions. On the other hand, VR tools might be used to simulate the experience of moving through and interacting with a $3 \mathrm{D}$ site layout environment. Planners and engineers at a job site will have displays that allow them to see simultaneously a site layout in progress and superimposed images of the proposed temporary facilities. They can query the system to show what type of temporary facilities should be installed at a particular time of the project construction. These queries can be time consuming ( planners have to extract information from a large number of drawings), but visualisation is a powerful and direct way to get access to the information required. Here, a combination of VR tools and AI techniques offer a chance to match the problem's complexity.

\section{Virtual Reality}

Virtual Reality (VR) is an advanced human-computer interface that simulates a realistic environment and allows participants to interact with it (Kellar, 1993). VR is a class of user interface which attempts to present large amounts of information in a natural manner, allowing the user to manipulate it using a more interactive method than the traditional graphical user interface. It does this by capitalizing on natural human attributes, such as the ability to manipulate objects in space (Latta, 1994).

Many of the initial ideas of virtual reality were set forward in the ' the ultimate display' (Sutherland, 1995). This is the first reference to the possibility of using computer generated virtual worlds. In his paper Sutherland initiated the idea of a computer generated world in which the user can see, and potentially hear, touch and manipulate objects.

It is important to distinguish VR systems from a simple 3-D computer aided design packages. In a VR system the subject becomes an active part of a simulated environment, being able to interact with objects and modify the model of the world. This definition requires the user to have influence over his environment which excludes simple systems designed only to view a three dimensional scene. Natural forms of interactions are used to make the system easier to use-instead of selecting an object with a mouse, the user can reach out a hand and pick the object up or turn it around to look at it from a different angle (Latta,

\section{3th ISARC}

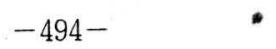


1994). The aim of this simulation is to induce a sense of presence where the user feels part of the simulated world. When this happens it is hoped that he will start to think more in terms of interacting with the objects in the simulated world and less in terms of interacting with a computer and thus be able to complete tasks faster and more efficiently.

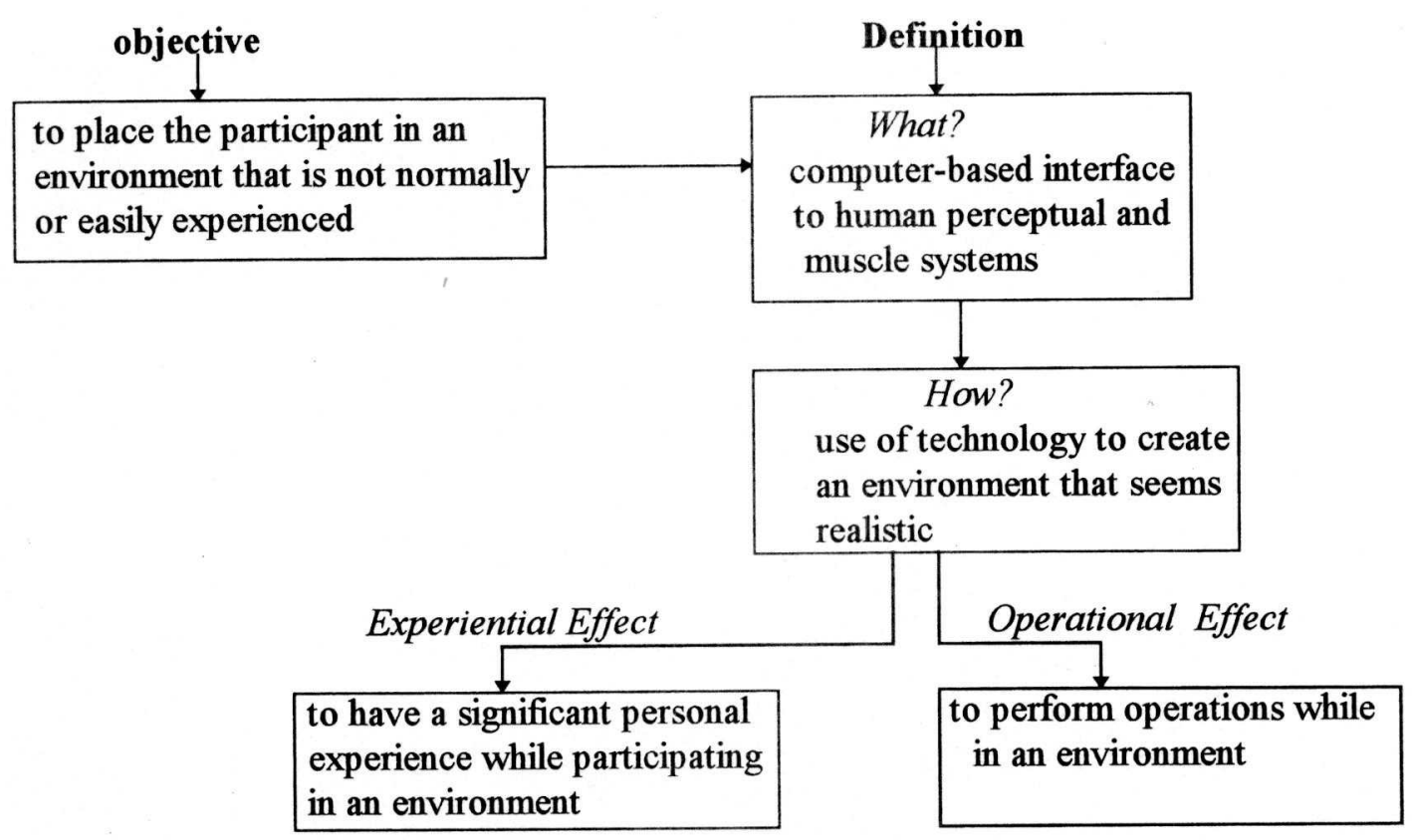

Fig. 1. Virtual reality objectives and definition ( Latta, 1994)

VR technology, under rapid development by the entertainment industry, is now trickling down to the construction industry community. Current uses of VR include visualising the physical layouts of buildings and process plants, reviewing designs for constructibilty, simulating construction tasks, and visualising construction schedules (Novitski, 1994). One of the applications of VR which has attracted most press coverage is architectural walkthrough (Retik, 1994). A system which allows the user to design the building, walk around it and attempt some of the intended uses for the building in the virtual world would be closer to using the full potential of VR. The use of VR systems can enhance the ability of a designer to manipulate and explore objects in three dimensions. The benefits of VR as a powerful communication tool are immediate. Unlike a collection of drawings, it's complete and unambiguous, however is not going to replace the construction experience but to complement it.

\section{Knowledge Elicitation}

The underlying objective of this research is to develop a conceptual model for site layout planning. Thus, the expertise does not need to be very detailed in the field, but rather, enough knowledge to represent and solve the problem of site layout.

Domain experts usually possess conceptual models which they use to represent; understand and solve problems in their respective domains. The first problem in site layout knowledge 
elicitation is understanding the differences and relations between the concepts and strategies used by planners. The following questions will be used to carry this task.

i- how is the site layout domain mapped out in terms of significant concepts and how are these related?

ii- what basic strategies do site layout planners use in performing the planning task and how do they break them down into sub-tasks?

iii- what influences their planning methods?

In this initial phase of the model development knowledge elicitation is being carried out by literature review. The second phase will be to validate and expand this knowledge using interview techniques.

The site layout information is modelled as objects with attributes which have values. Attribute values can be data (e.g., size of temporary facilities, optimum walking distance, etc.,) or programs. These objects can 'send messages' to each other, passing data or invoking actions. Objects are organised in a hierarchical fashion with one-to-many-and many-to-one links, and both attributes and their values can be inherited from higher level objects in the hierarchy. As an example, Fig. 2 shows an object frame for storage class. The frame contains no attributes or slots, but has sub-class objects (e.g., timber storage, cement storage, tool storage, etc.) Slots or attributes are created in member object-frames of the class object storage.

object name: storage

type: class

members: timber storage, cement storage, etc..

IsA: a site layout

\section{Fig. 2. Storage object frame}

object name: timber storage

IsA: a site layout, storage

members:

attributes/slots:

type of timber: frames for windows and doors

size: $30 \mathrm{~m}^{2}$

shape: rectangle

walking distance: $200 \mathrm{~m}$

period of storage: 5 weeks

location:

etc..

Fig. 3. Timber storage object frame 
Fig. 3 shows the timber storage object frame as a parent or child of the storage class object frame. The timber storage object frame contains attributes or slots that define the properties of the timber storage area. In this manner it is possible to add as many attributes that are relevant to the site layout process as required.

\section{Site layout Knowledge Base}

Failure to give due consideration to site layout will result in double handling, excessive walking, and many other wasteful practices which lead to low productivity. The storage location of on site materials, and where equipment and tools should be located at a job site all have an affect on operative productivity. If the materials storage location is such that workers have to continually walk long distances to get needed materials, hours of costly non-productive labour time will result. Similarly, if materials are stored away from the place of their subsequent fabrication, they will need to be unnecessarily double-lifted. Also poor positioning of labour support facilities, such as parking lots, change house, and toilets, can increase non-productive time with a corresponding reduction of direct time. Hence, rates of labour production during direct time be expected to vary with the labour force morale. Higher morale is anticipated if worker facilities are convenient and well maintained. Bad site layout will result in overcrowded areas due to : 1) increased density of personnel in one area of work and 2) the ever-increasing amounts of physical components and debris obscuring access to work areas on the site. Congestion of work areas is a very destructive productivity factor to plant as well as to the labour force. Ideally personnel should have a working space area of at least 10 square meters per person. Therefore, quantification of some of the site layout factors is dependent on horizontal and vertical distances form material location to work area, primary method of material supply, positioning of worker support facilities and working space. The following are some quantitative data on site layout factors (Thomas, 1990, Adrian, 1987, Borcherhing, 1981):

- man-hour loss due to overcrowded work areas $=5$ per week.

- loss per day due to travel carrying tools, materials, equipment or walking empty handed $=12.4 \%$ loss of day work.

- loss per day due to transport carrying tools, materials and equipment $=4.6 \%$ loss of day work.

- approximately $7 \%$ of a day is non-productive because of a non optimal site layout.

Site access: Productivity decrease because of site inaccessibility, e.g., storing heavy equipment in the path of workers may increase the chance of injury and hinder workers operations. Loss of labour productivity can result also from restricted access due to blasting and associated dust, fumes, blocked passage ways, presence of other personnel, and interference of construction operations. If construction roads are well maintained and dust is controlled and if working areas are shaped, drained, and safety hazards reduced, movement will be facilitated.

Site storage areas: The size of the immediate storage area must be adequate to permit reasonable access to the material and to preclude double handling or ineffective handling methods. Also, an essential part of the site layout task is that of determining the storage location for materials. Frequently materials are unnecessarily lifted and stored at a site. The storage area must be neat 
and easy for materials to be identified and retrieved. One of the productivity studies (Rad, 1980) indicated that on-site materials are lifted as many as six times.

\section{Structure of the Model}

The model consists of an intelligent data base and a user interface program. In turn, the data base consists of graphical models and a site facility knowledge base, as shown in Fig. 3.

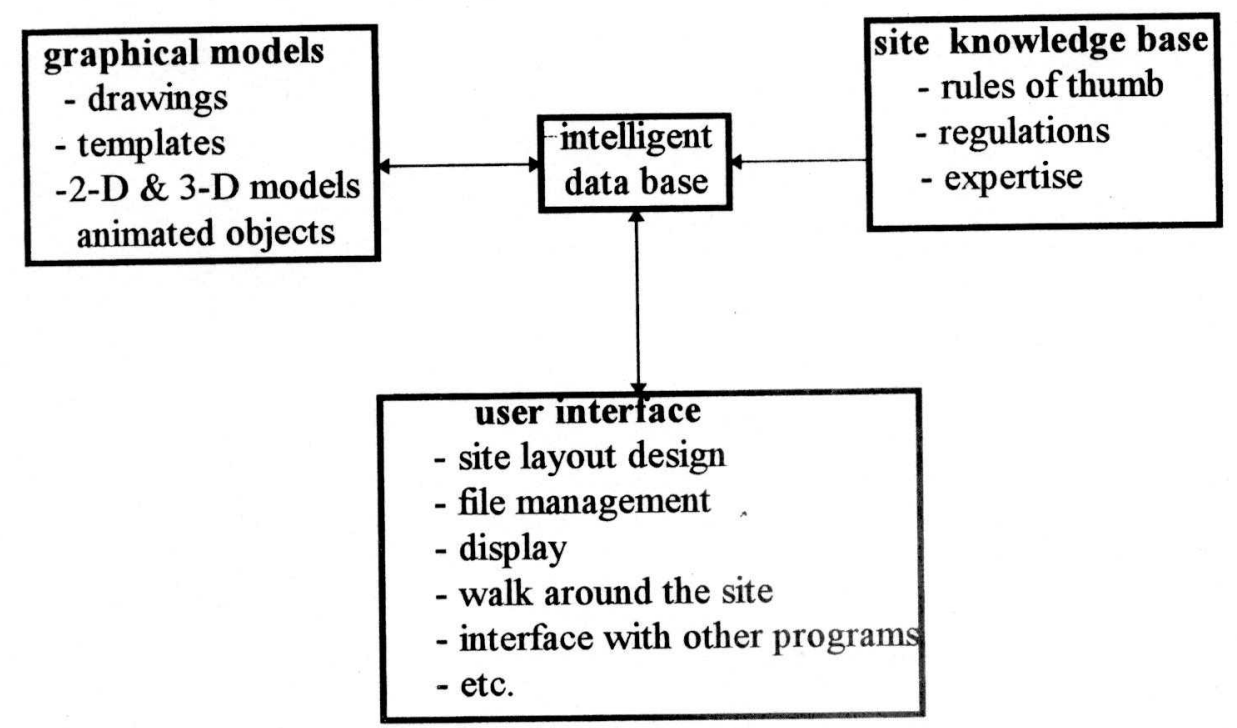

Fig. 4. The structure of the model

The graphical models contain templates, two dimensional (2-D) and three dimensional (3-D) representation. Example of the facilities that might be included in the models are ( Gibb, et al. 1995).

\section{Labour related facilities}

- canteen

- site offices

- access and security

- toilets/washrooms

- car parking

- etc.

Material related facilities

- deliveries access

- good hoists

- storage areas

- etc.

The location and sizing of these facilities will be produced by interaction between the user and the intelligent knowledge base to establish the particular rules and constraints which apply to a particular site.

There are three possible methods by which a site layout could be electronically created. Drawings, templates; and 2-D and 3-D models. Equipment positioning, access, laydown areas, overhead utilities and site topography are all areas which are might be best analyzed through VR models. The development of 3-D CAD and VR systems has made this a much 
simpler, cheaper and desirable option. The use of VR systems on personal computers has become much more accessible in the last few years with the swift development of both hardware and software. The 3-D animated site layout facility models can be construct in two stages. First, the geometrical shape of the site facilities are created by CAD or Superscape virtual reality software as objects. Once a shape of a facility is created, colors and animation features are then added to the 3-D models. In the second stage, the 3-D objects will be used to build up a virtual site layout. Site facilities are constructed from objects, individual objects can, in turn, be combined to make more involved and complex objects. The size and position of these objects in a virtual site layout world will be controlled via IF-THEN rules written in a low level programming language. For example, the system, will not allow the storage of flammable materials to be near electrical installations. The knowledge elicitation process and some of the site layout knowledge acquired for this model are described above.

The user interface module provides a textual and graphical interaction between the system and the user. As most computer applications are designed to be used by individuals with little computer literacy, user friendly facilities, such as on line help, explanation and error recovery, are essential parts of the user interface. In this application emphasis will be placed on realistic graphical presentation and the development of an interface suitable for construction industry practitioners. A visualiser software package can be used to display and interact with the site virtual world created by the user using pre-defined 3-D animated models. This approach offers planning engineers the opportunity to get around the site and experiment with the site layout plans without risk and expense of taking the wrong decisions at the pre-construction stage.

\section{Conclusion}

VR is a combination of computer technologies that simulates the experience of moving through and interacting with a $3 \mathrm{D}$ environment. As the technology improves, managers, engineers, architects, and planners will be able to move through and manipulate site facilities, and predict problems before construction starts, before they become much more expensive to re-allocate. This research is concentrating, in the first instance, on the development and knowledge elicitation of a theoretical model for site layout visualisation. This will pave the way for the second phase which will transform the model into a computer virtual environment.

\section{References:}

Adrian, J. (1987), Construction productivity improvement, Elsevier science $\mathrm{Pb}$ Co., New York.

Borcherhing, J. B. and Garner, D. F., (1981), Work force motivation and productivity on large jobs, Journal of Construction Engineering \& Management, ASCE, 107,3, 443-453

Cheng, M. and O'Connor, J. (1994), Site layout of construction temporary facilities using an enhanced-geographic information system (GIS), Automation in Construction, vol. 3, 11-19. 
Gibb, A. G. F. (1995), Site layout and facilities. In: Neals R. H. (ed), Managing Construction projects: An overview. ILO, Geneva, 83-113.

Gibb, G.F. and Knobbs, T. (1995), Computer -aided site layout and facilities planning, in ARCOM proceedings, 541-5504.

Kahaner, D., (1994), Japanese activities in virtual reality, IEEE Computer Graphics \& Applications, January, 75-78.

Kellar, D. (1993), Virtual Reality: Real money, Computerworld, Nov.15, pp.70.

Latta, J. and Oberg, D. (1994), A conceptual virtual reality model, IEEE Computer Graphics \& Applications, January, 23-29.

Novitski, B. (1994), Virtual Reality: toward a new millennium, A/E/C/ Systems Computer Solutions, January-February, 34-39.

Rad, P. F. \& James, B. M. (1983), The layout of temporary construction facilities. Cost Engineering, 25, 2, 19-27.

Rad, P. F. (1980), Analysis of working space congestion from scheduling data, Trans. Amer. Cost Engineers, Vol, nn, F3-F3.7.

Retik, A and Hay, R. (1994), Visual simulation using virtual reality, Tenth Annual Conference, ARCOM, September, 537-546.

Sutherland, I. E. (1965), The Ultimate display, in proceedings IFIP Congress Vol 2. PP. 506-508

Thomas, H. R, et al. (1990), Modelling construction Labour productivity, Journal of Construction Engineering \& Management, ASCE, 116,4.

Tommelein, I. D. (1994), MoveCapPlan: An integrated system for planning and controlling construction material laydown and handling, Computing in Civil Engineering, ASCE, 2,1172-1179.

Tommelein, I. D. 1991 \& Zouein, P.P (1993), Interactive dynamic layout planning, Journal of Construction Engineering \& Management, ASCE, 119,2, 266-287.

Tommelein, I. D., Levitt, R. and Hayes-Roth, B. (1992), SIGHTPLAN model for site layout, Journal of Construction Engineering \& Management, ASCE, 118,4, 749-766. 